\title{
IMPORTÂNCIA DA INTERDISCIPLINARIDADE NA FORMAÇÃO DOCENTE NO PROCESSO DE LETRAMENTO
}

\section{ARTIGO DE REVISÃo}

SANTOS, Antonia do Nascimento Pereira ${ }^{1}$, RODRIGUES, Juracy Santana ${ }^{2}$,FARIAS, Ana Rosa Santos ${ }^{3}$

SANTOS, Antonia do Nascimento Pereira. RODRIGUES, Juracy Santana. FARIAS, Ana Rosa Santos. Importância Da Interdisciplinaridade Na Formação Docente No Processo De Letramento. Revista Científica Multidisciplinar Núcleo do Conhecimento. Ano 06, Ed. 05, Vol. 01, pp. 66-77. Maio de 2021. ISSN: 2448-0959, Link de acesso: https://www.nucleodoconhecimento.com.br/educacao/processo-deletramento, DOI: 10.32749/nucleodoconhecimento.com.br/educacao/processo-deletramento

\section{RESUMO}

O trabalho de pesquisa objetivou propor reflexões para compreender como a proposta interdisciplinar pode contribuir para o aperfeiçoamento da formação docente, ao assumir os enfrentamentos que a escola possui em relação ao ensino e aprendizagem. Nesse contexto, a abordagem interdisciplinar, propõe uma nova possibilidade para que os profissionais da educação reflitam sobre as práticas pedagógicas que envolvem o ato de ler e escrever no processo de letramento. Assim, considerando essa problemática, questionamos: Qual a importância da interdisciplinaridade na formação docente na construção do processo de letramento?

\footnotetext{
${ }^{1}$ Especialista em Educação Especial e Inclusiva e Neuropsicopedagogia.

${ }^{2}$ Especialista em Docência do Ensino Superior.

${ }^{3}$ Especialista em Educação Ambiental.
}

RC: 84294

Disponível em: https://www.nucleodoconhecimento.com.br/educacao/processo-de-letramento 
Os encaminhamentos metodológicos dessa pesquisa são de abordagem qualitativa, de cunho bibliográfico, que respaldam as discussões de autores que destacam os desafios do saber docente na construção do processo de letramento. Tendo em vista a importância a formação do professor nos processos que envolvem a leitura e a escrita, busca-se a adequação de um currículo flexível e dinâmico, que contemple os diversos campos dos saberes de forma articulada e não estática, como preconiza a tradição cartesiana. Além das contribuições de abordagens sócio-históricas, que se constituem em um relevante suporte para entender, o quanto as interações sociais promovem o desenvolvimento de competências dos diversos saberes que permeiam o processo de letramento.

Palavras-chave: Interdisciplinaridade, Formação do Professor, Letramento.

\section{INTRODUÇÃO}

A educação tradicional em toda a sua trajetória preocupou-se em ensinar os conteúdos de forma fragmentada e conteudista, sem a preocupação de construir o conhecimento articulado para que o aluno pudesse compreender a importância da aprendizagem em uma perspectiva interdisciplinar. Em uma época marcada pelo avanço tecnológico, a escola é convocada a assumir novos desafios, sendo necessário repensar suas práticas educativas, para garantir a formação de cidadãos autônomos, criativos e solidários.

Nota-se que muitas crianças finalizam o Ensino Fundamental II, sem o domínio da tecnologia do alfabeto, apesar de o acesso à educação ser uma realidade na sociedade brasileira. No contexto atual percebe-se que os educandos enfrentam inúmeras dificuldades em relação à leitura e a escrita - situação que se alarga com maior complexidade nas séries finais da Educação Básica, o que terá grandes implicações para esses alunos a inserir-se no mercado de trabalho formal.

Por conta dessa problemática, o estudo de pesquisa tem o objetivo de propor aos professores algumas reflexões que possam mediar o conhecimento por meio do

RC: 84294

Disponível em: https://www.nucleodoconhecimento.com.br/educacao/processo-de-letramento 
ensino interdisciplinar, em que o currículo não possa ser visto de maneira fragmentada, mas sim imbricado em todas as áreas do saber.

Este estudo acerca do ensino interdisciplinar fundamenta os seus encaminhamentos metodológicos através da abordagem de caráter qualitativa através da pesquisa bibliográfica de importantes teóricos como Japiassu (1976), Fazenda (1993; 1994; 2003), Soares (2001; 2004; 2006), Luck (1994; 2013), Vygotsky (1984), Durkheim (2010) dentre outros autores que veem no trabalho, que relaciona duas ou mais disciplinas, uma nova proposta para que os profissionais da educação reflitam sobre a importância da formação docente ao assumir os novos desafios que a escola impõe em relação ao processo de letramento. Além do mais, entende-se que as contribuições de abordagem sócio-históricos se constituem num suporte relevante para compreender o quanto as interações sociais contribuem com o aprendizado dos indivíduos ao desenvolver competências para entender os diferentes saberes disciplinares, que permeiam o processo de letramento.

\section{INTERDISCIPLINARIDADE E OS DESAFIOS NA CONSTRUÇÃO DO SABER}

A proposta interdisciplinar surge em meio aos conflitos gerados pela Primeira e Segunda Guerra Mundial, concomitante às catástrofes e as crises energéticas que transformaram as relações sociais no espaço e no tempo e ganha, na década de 60, novos rumos na Europa, quando professores e alunos do ensino superior opuseramse a fragmentação do saber, simbolizando com isso, o retorno do homem ao seu meio social na busca do conhecimento holístico que se concebe a dimensão da realidade em sua amplitude.

Por outro lado, os estudos nessa área foram disseminados por George Gusdorf (1964) na mesma década, o que influenciou os maiores teóricos brasileiros no meio acadêmico para que essa ideia fosse trabalhada em sala de aula, de forma que os alunos compreendessem as temáticas atuais com possibilidades de letrar-se em sua

RC: 84294

Disponível em: https://www.nucleodoconhecimento.com.br/educacao/processo-de-letramento 
totalidade. Diante dessa realidade, Trindade (2013), mostra que Japiassu (1976) foi o primeiro pesquisador a escrever sobre o assunto, publicou o livro Interdisciplinaridade e patologia do saber (1976), no qual apresenta os principais problemas que envolvem o tema, as conceituações existentes, além de fazer uma reflexão sobre a metodologia interdisciplinar baseada nas experiências realizadas até então.

Já Fazenda (1999), encaminhou seus estudos no campo pedagógico e mostrou que o termo sofreu várias distorções, como um modismo, uma palavra de ordem a ser explorada. Por essa razão, a ideia de interdisciplinaridade transita no meio educacional sem muita perspectiva. A autora postula que a escola precisa entender que essa proposta visa a compreensão integral do saber ao envolver o aluno no mundo do real conhecimento, o que permite a sua atuação como protagonista da própria história. Nesse contexto Japiassu (1976) afirma que:

A interdisciplinaridade define e se elabora por uma crítica das fronteiras das disciplinas de sua compartimentação, proporcionalmente uma grande esperança de renovação e mudança no domínio da metodologia das Ciências Humanas, (JAPIASSU, 1976, p.54).

Japiassu (1976), mostra que o trabalho interdisciplinar não se realiza apenas no domínio da informação recíproca entre os estudos. Contudo, se houver um confronto da totalidade das disciplinas cooperantes a qual cada uma se arrisca e se modifica pela outra, evidência então uma perspectiva da totalidade das temáticas de ensino trabalhando em colaboração uma com a outra. Percebe-se também, que os fundamentos epistemológicos trabalhados por Japiassu na academia, tenham construído bases para que a tendência interdisciplinar fosse aprimorada no campo pedagógico nos aportes de um currículo flexível, que permita conexões entre os saberes que são ministrados em sala de aula e as experiências de vida dos alunos, para que eles percebam a importância do conhecimento a partir das relações sociais que mediam as várias fases do letramento. Desse modo, segundo Schindler (2005).

O elo entre as disciplinas cria um espaço para o fortalecimento da interdisciplinaridade, que não é mais do que o conhecimento

RC: 84294

Disponível em: https://www.nucleodoconhecimento.com.br/educacao/processo-de-letramento 
sistemático, que busca sentido na totalidade, respeitando a especificidades das disciplinas, viabilizando a possibilidade de pensar, que possa complementar em outro desenvolvimento, assim a inteligência (SCHINDLER, 2005, p.11).

Cabe ressaltar que na tentativa de melhorar o ensino aprendizado, boa parte dos professores, ainda enfrentam desafios de compreender o que realmente significam as terminologias que envolvem a proposta em estudo, como multidisciplinaridade, interdisciplinaridade e transdisciplinaridade. Magalhães (2009), em seus estudos, enfatiza que Japiassu (1976), diferencia o termo multidisciplinaridade de pluridisciplinaridade. Para a multidisciplinaridade trata-se de um sistema em que as disciplinas trabalham o mesmo tema, no entanto, não há nenhuma cooperação entre elas. Porém, o tema comum aparece como meio para se chegar ao objetivo original. Nesse sentido, não há entrelaçamento do tema em questão, o que não ocorre de fato, é a cooperação das disciplinas em sua totalidade. Já a pluridisciplinaridade aproximase da ideia de cooperação entre o assunto que é ministrado por cada professor, todavia, cada uma trabalha direcionada ao seu fim original, que prioriza o tema como um artifício da disciplina (JAPIASSU, 1976).

$\mathrm{Na}$ abordagem interdisciplinar baseada nos estudos de Japiassu (1976), as disciplinas não reduzem a metodologia de uma ciência apenas, mas consegue perceber a cada temática como um todo e não apenas fragmentos desta. Por conta disto, é necessário que as várias disciplinas, estabeleçam pontes entre si e não uma simples adição ou coleção. Com base nas discussões de Japiassu (1976):

Será absolutamente falso postular que a interdisciplinaridade, possa resultar da simples reunião adição ou coleção de vários especialistas, ou da simples tomada de posição teórica de especialistas que só se encontram reunidos ou justapostos, por razões que não tem muito a ver com o interesse da pesquisa (JAPIASSU, 1976, p.54).

Partindo dessa concepção, os estudos conseguem intercalar-se entre si, a ponto de o aluno compreender que o conhecimento está imbricado de tal forma, que não é possível ver a disciplina pela disciplina. Condição essencial para que os discentes e os docentes possam repensar que ações relevantes poderão ser construídas a partir

RC: 84294

Disponível em: https://www.nucleodoconhecimento.com.br/educacao/processo-de-letramento 
do amadurecimento de ideias, que se remetem ao amplo arcabouço de saberes que direcionam o engajamento das infindas etapas do processo de letramento, que acompanham as vivências do cotidiano do aluno.

Corroborando a ideia de Japiassu (1976), Fazenda (2013), aponta que a interdisciplinaridade é definida como interação existente entre duas ou mais disciplinas. Verifica-se que, tal definição pode nos encaminhar da simples comunicação de ideias, até a integração mútua dos conceitos através da epistemologia, assim como os dados da organização da pesquisa e do ensino relacionando-os. Enfim, é relevante atentar que a complexidade do trabalho interdisciplinar emerge da possibilidade de entender que essa proposta não é algo pronto e acabado, onde as práticas educativas são realizadas mecanicamente sem articulação com a realidade do aluno e do mundo em que ele vive.

\section{FORMAÇÃO DO PROFESSOR E OS ENTRAVES NO ENSINO INTERDISCIPLINAR}

Diante das inúmeras dificuldades que o professor encontra para trabalhar com a proposta interdisciplinar, percebe-se que as universidades não têm cumprido o seu papel como formadoras de saberes. Embora a prática interdisciplinar não seja recente no campo epistemológico e pedagógico, nota-se que as experiências voltadas para o desenvolvimento de práticas pedagógicas educativas não são trabalhadas de forma a perceber o intercruzamento dos saberes do processo de letramento. Para Durkheim (2010), é relevante repensar na formação docente com mudança de atitudes dos professores, alunos, assim como a organização do fazer pedagógico.

Neste aspecto, Japiassu (1976), aponta que o trabalho interdisciplinar consiste, primordialmente em lançar uma ponte para religar fronteiras que haviam sido estabelecidas entre as disciplinas, como objetivo de assegurar a cada um seu caráter propriamente positivo. Trabalhar nessa perspectiva exige criatividade, tempo para articular as ideias e aperfeiçoamento em vistas a interação dos educandos, com

RC: 84294

Disponível em: https://www.nucleodoconhecimento.com.br/educacao/processo-de-letramento 
diferentes leituras de mundo que, dessa forma, possam contribuir com os distintos níveis de letramento, que os sujeitos enfrentam mediante as suas relações sociais.

Diante da proposta de Japiassu (1976), observa-se que trabalhar na perspectiva interdisciplinar, é compreender o que de fato esta ideia significa e os elementos que devem ser potencializados. Por ser um trabalho que reorganiza o conhecimento através de unicidade, é necessário que os professores criem estratégias e conheçam toda trajetória das ações que são desenvolvidas em sala de aula, para que este conhecimento transcenda os "muros" da escola.

O trabalho de religar as fronteiras do conhecimento proposta por Japiassu (1976), coaduna com a ideia de Barbosa (2008), que enfatiza a importância de o professor aperfeiçoar-se no ensino da arte, para que o aluno possa integrar esses conhecimentos a outros tão necessários a apropriação crítica do ensinoaprendizagem. Desse modo a autora enfatiza que:

A interdisciplinaridade, portanto, tem como objetivo integrar a colcha de retalhos de competências altamente desenvolvidas e de interesses diversificados e muitas vezes antagônicos. Esta interação é uma organização que tem lugar na mente do aluno, provocada pela forma com o conhecimento é apresentado (BARBOSA, 2008, p.11).

Neste aspecto, trabalhar nessa dimensão, não implica necessariamente em fazer parte de um projeto que precisa cumprir etapas e produção de ações, é preciso sim, compromisso diante do que se pretende conquistar. Diante disso, Luck (1994), aponta que o exercício pedagógico do professor compromissado com o processo implica: na vivência do espírito de parceria, de integração entre teoria e prática, e realidade objetividade e subjetividade, ensino e avaliação, reflexão e ação.

Nesse contexto, Pombo (2005) afirma que por conta da fragmentação do saber que existe nas universidades, os docentes saem da academia e levam para a sala de aula, práticas educativas pautadas na tradição cartesiana, o que não permite ao estudante estabelecer o diálogo com outras disciplinas. Diante dessa situação, o papel das universidades na condição de formadora do saber, importa realizar a sua função social

RC: 84294

Disponível em: https://www.nucleodoconhecimento.com.br/educacao/processo-de-letramento 
na formação de sujeitos que atuem como seres reflexivos e críticos em um mundo que impõe saberes interdisciplinares no contexto do processo de letramento. Nesse sentido:

\begin{abstract}
A universidade enquanto escola, ela tem que preparar para interdisciplinaridade, uma vez que todos os encaminhamentos epistemológicos que são vivenciados na academia, precisam ser trabalhados de forma objetiva que os alunos percebam a importância do engajamento disciplinar em todas as áreas do conhecimento (POMBO, 2005, p.12).
\end{abstract}

Assim, percebe-se que 0 engajamento dos educadores e 0 permanente aperfeiçoamento dos novos saberes necessitam ser ressignificados, para que o conhecimento seja visto de forma integral, e não isolado, para que desse modo, os estudantes vejam no letramento uma nova possibilidade para intervir no mundo através do aprendizado interdisciplinar.

\title{
4. ALFABETIZAÇÃO, LETRAMENTO E OS DESAFIOS DOS SABERES INTERDISCIPLINARES
}

No contexto da interdisciplinaridade, o conceito de alfabetização não pode ser trabalhado isoladamente, mas sim na perspectiva de um letramento que proporcione o exercício do código escrito de forma competente e interativa. Como indica Soares (2001).

\footnotetext{
Habilidades várias, tais como: capacidade de ler ou escrever, para atingir diferentes objetivos, para informar - se, para interagir no imaginário, no estético, para ampliar conhecimentos, para seduzir ou induzir, para divertir - se, para orientar-se, para apoio à memória (SOARES, 2001, p.92).
}

Assim como o termo interdisciplinaridade é difícil de ser compreendido no interior da escola, para Soares (2006), alfabetização, na maioria das vezes, é confundida com letramento revelando confusão ou superposição de conceitos, em que o ato de ensinar a ler e a escrever, mais do que possibilita o simples domínio de uma tecnologia, cria

RC: 84294

Disponível em: https://www.nucleodoconhecimento.com.br/educacao/processo-de-letramento 
condição para inserção do sujeito em práticas sociais de consumo e produção do conhecimento e em diferentes instâncias sociais e políticas.

Nessa abordagem, Durante (1998), mostra que a alfabetização e o letramento são conceitos que se processam, em diferentes etapas, na construção do conhecimento, pois, a partir do momento que o aluno decodifica e codifica o sistema alfabético, terá condições de intervir em várias situações do seu contexto social, já que, é neste momento, que a alfabetização se constitui numa extensão do processo de letramento.

Na compreensão de Durante (1998) o letramento é uma competência que requer do indivíduo a adequação de estruturas mentais que façam conexões com a tecnologia da leitura e da escrita, a ponto de compreender e interpretar os mais variados tipos textuais de forma a conseguir articular os vários saberes.

Ao atribuir valor aos processos sócio-históricos do letramento, a autora entende que esses processos extrapolam os muros da escola por encontrar nas

transformações que ocorrem na sociedade, condições para que o sistema simbólico da escrita seja usado nos mais amplos contextos sociais. Diante dessa visão dialética de mundo, Luck (2013) aponta:

Que o desafio apresentado à educação a fim de que contribuem para a formação de pessoas capazes de se defrontarem com os problemas do seu ambiente cultural e natural, consiste em que se apresente como ação educativa, dinâmica e dialética, visando desenvolver entre seus particulares a consciência da realidade humana e social, da qual a escola faz parte, mediante uma perspectiva globalizadora (LUCK, 2013, p.22).

A ideia globalizadora que Luck (2013) aponta, relaciona-se com o contexto interdisciplinar ao permitir que o aprendizado em sala de aula esteja relacionado as práticas da leitura e da escrita em várias situações do cotidiano, em que os conhecimentos poderão ser utilizados de maneira integrada. Diante disso, vale ressaltar que:

RC: 84294

Disponível em: https://www.nucleodoconhecimento.com.br/educacao/processo-de-letramento 
A interdisciplinaridade do ponto de vista da laboração sobre o conhecimento e elaboração do mesmo, corresponde a uma nova consciência da realidade, a um novo modo de pensar, que resulta no ato de troca, de reciprocidade e integração entre áreas diferentes de conhecimento, visando tanto produção de novos conhecimentos, como resolução de problemas, de modo global abrangente (LUCK, 2013, p.46).

É relevante atentar, que tanto o pensamento de Vygotsky (1984) e a abordagem de Durante (1998), demostram que as diferentes aprendizagens são mediadas pelas interações que ocorrem no meio sociocultural, condição que possibilita ao aluno questionar as verdades prontas, a ponto de construir novos caminhos para transformar o espaço da sua vivência, por meio da diversidade de saberes interdisciplinares que são construídos nas várias etapas do processo de letramento.

\section{CONSIDERAÇÕES FINAIS}

A proposta curricular desenhada pelos teóricos da interdisciplinaridade, impõem-nos, um novo olhar em relação à forma de ensinar e aprender letrando, para que os alunos sejam protagonistas da sua própria história, através do autoconhecimento do que se sabe e do que precisa aprender. Parte-se da constatação, de que o acesso à educação, tem permitido que os alunos avancem nas séries, mas retrocedam na construção de uma aprendizagem significativa. Por conta disso, é preciso que os agentes educativos criem possibilidades para que o educando encontre aportes necessários para que possam desenvolver as suas potencialidades. Assim, esperase que as ponderações apresentadas nesta pesquisa de revisão bibliográfica suscitem novas reflexões em meio aos novos desafios que a escola enfrenta em relação aos entraves no processo de letramento.

Por entender que a ideia interdisciplinar trabalha o conhecimento de forma articulada, importa a escola, fundamentar as bases do processo de letramento, não apenas na teoria, mas em ações efetivas, para que no futuro tenhamos cidadãos autônomos e criativos, que encontrem no domínio da tecnologia da escrita saberes que perpassem aos mais diversos territórios do letramento. Desse modo, o aprendiz será capaz de

RC: 84294

Disponível em: https://www.nucleodoconhecimento.com.br/educacao/processo-de-letramento 
atender às novas demandas sociais, proporcionadas pela nova cultura digital, que impõe novos ritmos aos indivíduos na compreensão do mundo, não de forma fragmentada, mas sim, em sua totalidade.

É imprescindível também, que a luta pala educação de qualidade pressuponha transformação concreta entre os agentes educativos que fazem parte da comunidade escolar, o que implicará a troca de experiências e a cooperação entre áreas do conhecimento, não na superposição de saberes, mas sim no compartilhamento de ideias, onde os educandos se tornarão coautores do conhecimento por meio das práticas sociais vivenciadas pelo processo de letramento.

\section{REFERÊNCIAS}

DURANTE, MARTA. Alfabetização de adultos: leitura e produção de textos. Porto Alegre: Grupo A, 1998.

DURKHEIM, Émile; FILLOUX, Jean Clande. Tradução: Celso do Prado Ferraz de Carvalho, Miguel Henrique Russo. Recife: Fundação Joaquim Nabuco, Editora Massanganos, 2010 - (Coleção Educadores).

FAZENDA, IVANI. Interdisciplinaridade - transdisciplinaridade: visões culturais e epistemológicas. In: FAZENDA, Ivani (Org.). O que é interdisciplinaridade? 2. ed. São Paulo: Cortez, 2013.

. Interdisciplinaridade: um projeto em parceria. São Paulo: Layola, 1993.

. (org.). Práticas Interdisciplinares na escola. 2.ed. São Paulo: Cortez, 1994.

JAPIASSU, Hilton. Interdisciplinaridade e patologia do saber. Rio de Janeiro, 1976.

RC: 84294

Disponível em: https://www.nucleodoconhecimento.com.br/educacao/processo-de-letramento 
LUCK, HELOISA. Pedagogia interdisciplinar: Fundamentos teóricos e metodológicos. Petrópolis, Rio de Janeiro. Vozes, 2013.

MAGALHÃES, Everton Moreira. Interdisciplinaridade: por uma pedagogia não fragmentada. Junia, Mato Grosso. Minhateca [2009], p. 1-5. Disponível em: http://www.ichs.ufop.br/memorial/trab/e 3. Acesso em 28 fev. de 2021.

POMBO, Olga. Interdisciplinaridade e integração dos saberes. Lince em Revista, v.1, n.1 março 2005.p/12. Disponível em: http: //www.ibect.br/ Acesso em 19 jan. de 2021.

SCHINDLER, Jaqueline César. Interdisciplinaridade. In. Cloux, Raphael Fontes. (Org.). Ensaios sobre a educação: tecnologia, políticas, alfabetização, EJA, pedofilia, interdisciplinaridade e literatura - Salvador (BA): KAWO - Kabiyesile, 2015.

SOARES, Magda. Letramento e Escolarização. In: RIBEIRO, Vera Masagão (Org.). Letramento no Brasil, reflexões a partir do INAF 2001. São Paulo: Global, p. 92, 2001

SOARES, Magda. Letramento e Escolarização. In: RIBEIRO, Vera Masagão (Org.). Letramento no Brasil. São Paulo: Global, p. 07, 2004.

SOARES, Magda. O letramento e a alfabetização - Qual a diferença entre a alfabetização de criança e a de jovens e adultos? Letra $\mathrm{A}-\mathrm{O}$ jornal do alfabetizador, Belo Horizonte, ano 02, p. 03, jun/ jul. 2006. (Edição especial sobre as ciências).

TRINDADE, Diamantino Fernandes. Interdisciplinaridade; Um novo olhar sobre as ciências. In: FAZENDA, Ivani (Org). O que é interdisciplinaridade?: 2. Ed. São Saulo: Cortez, 2013.

VYGOTSKY LEV. SEMYONOVICH. A formação social da mente. São Paulo. Martins Fontes, 1984.

Enviado: Março, 2021.

Aprovado: Maio, 2021.

RC: 84294

Disponível em: https://www.nucleodoconhecimento.com.br/educacao/processo-de-letramento 
RC: 84294

Disponível em: https://www.nucleodoconhecimento.com.br/educacao/processo-de-letramento 